\title{
Pornoerótica latinoamericana: subversión en la narrativa de mujeres en el exilio
}

\author{
Mónica OJEDA FRANCO \\ Universidad Complutense de Madrid
}

\section{RESUMEN}

Este ensayo aborda el tema de la escritura 'pornoerótica' de mujeres latinoamericanas en el exilio durante los años ochenta -época de caída de las dictaduras militares y, por lo tanto, de crítica a la censura, de apertura a debates de género y de exploración literaria por parte de mujeres-, a través de una lectura política de Lo impenetrable (1984) de Griselda Gambaro, La nave de los locos (1984) de Cristina Peri Rossi y "Cambio de armas" (1982) de Luisa Valenzuela.

Palabras clave: narrativa pornoerótica, escritura de mujeres, exilio, dictaduras latinoamericanas.

\section{Latin American Pornerotic: Subversion in the Narrative of Women in Exile}

\begin{abstract}
This essay addresses the 'pornerotic' writing of Latin American women in exile during the 80 's -when military dictatorships started to fall and criticism of censorship, gender debates and literary exploration by women writers stood strong- through a political lecture of The Impenetrable Madame X (1984) by Griselda Gambaro, The Ship of Fools (1984) by Cristina Peri Rossi and "Change of Weapons" (1982) by Luisa Valenzuela.
\end{abstract}

Keywords: pornerotic narrative, women writing, exile, Latin American dictatorships.

SUMARIO: 1. La mirada latinoamericana. 2. Literatura pornoerótica de los años ochenta. 3. Androginia y bisexualidad: Lucía y Madame X. 4. La censura y la escritura del daño. 5. Conclusiones.

Escribir el cuerpo significa construirlo y también deconstruirlo. Es por eso que la pornografía literaria representa un tabú y, ciertamente, queda exiliada de la pirámide de prestigio. Matthew Kieran en su ensayo "Pornographic art" (2001) dice que en el habla coloquial referirnos a un arte pornográfico es, en realidad, construir un oxímoron. En el mejor de los casos las representaciones pornográficas solo pueden ser vistas -desde el imaginario cultural- como un arte malo, superficial, carente de trascendencia y, en el peor, como producciones sobre los aspectos más mundanos y denigrantes de la carne. En tanto que lo pornográfico es obsceno y lo obsceno es, en palabras de Naief Yeyha "aquello que se sitúa fuera de los márgenes 
de lo representable" (2012: 30), hablar de un arte pornográfico es poner las manos sobre un tema polémico. De ahí que exista su contrapuesto: el erotismo. Yeyha escribe en su ensayo Pornografía (2004) que lo pornográfico no se define por lo que es, sino por lo que causa, es decir que se trata de una categoría móvil, mutante, que cambia según la época y su marco moral de lo permisible. Tanto Kieran como Sontag, por otra parte, señalan que en el imaginario común lo pornográfico es aquello que tiene como único fin provocar excitación sexual. Sin embargo, las 'novelas obscenas' no pueden ser pensadas exclusivamente desde su intencionalidad. Susan Sontag reflexiona sobre esto en su ensayo "La imaginación pornográfica" (1967), en donde hace referencia a la dificultad que la crítica y que los lectores encuentran al momento de afrontar un producto que es artístico y, simultáneamente, pornográfico. El problema está en que la sombra de la palabra obscenidad parece entrar en contradicción con el carácter elevado del arte: mientras que la pornografía pervierte, deprava, tuerce, el arte humaniza, dignifica y engrandece. Esta visión moral de lo artístico construye definiciones a partir de los efectos que provoca determinado producto cultural en sus consumidores sin pensar en el producto ni en sus características propias. Lo pornográfico, que puede mostrarse en cualquier forma, aparece fuera de la disquisición artística no porque su naturaleza le impida ser una expresión del pensamiento -normalmente se cree que es una expresión de los más bajos instintos y que carece de ideas-, sino por su carácter blasfemo y, en general, inmoral: "La pornografía es el género fuera de los géneros, aquel que más que definir estigmatiza, ese que no permite fusiones con otros géneros porque convierte en pornografía todo lo que toca" (Yeyha, 2012: 15).

\section{La mirada latinoamericana}

En Latinoamérica las nociones de ambos términos - pornografía y erotismo- no han generado mayor debate porque el escenario de discusión difiere significativamente. El Periquillo Sarniento de José Joaquín Fernández de Lizardi, considerada la primera novela latinoamericana, se publica en 1816 en el marco de las guerras por la independencia a lo largo del continente. Las siguientes producciones narrativas, hasta 1940 aproximadamente, se encargaron de reflexionar en torno a la problemática de civilización vs. barbarie; surge con fuerza el realismo social y el indigenismo como formas literarias de búsqueda y de construcción de una 'verdadera identidad latinoamericana', de reivindicación social de las clases históricamente oprimidas, de distanciamiento de España y de Europa en general, etc. De modo que la narrativa latinoamericana tuvo otro tipo de preocupaciones esenciales que hicieron que el erotismo, aunque incluido dentro de obras cuya temática no se circunscribía a la exploración de dicha categoría, quedara relegado a un segundo plano. No es sino hasta 1940 que los escritores, impulsados por la llegada de las ideas vanguardistas, comenzaron a interesarse por la experimentación formal y por otros temas que no fueran los nacionales. Si bien en poesía la irrupción de lo erótico puede ser rastreada desde mucho antes, en narrativa solo se piensa el 
cuerpo, su lugar en el mundo y sus representaciones, como centro temático, en el siglo XX.

Simultáneamente, a principios de siglo, los movimientos feministas del primer mundo exigieron repensar la representación de la mujer en el imaginario cultural europeo y norteamericano, mientras que en Latinoamérica se formaron las primeras organizaciones y agrupaciones feministas. Poetas como Delmira Agustini, Juana de Ibarbourou, Alfonsina Storni, Alejandra Pizarnik, Gabriela Mistral, Lydia Dávila, Dolores Veintimilla, entre otras, introdujeron, en este escenario, a la mujer como posible sujeto de deseo. En 1960 las escritoras latinoamericanas empezaron a publicar novelas y cuentos cuyo eje central era el erotismo ${ }^{1}$-aunque Armonía Somers, escritora uruguaya, publicó una novela erótica, La mujer desnuda, en 1950-. Si bien la palabra 'pornografía' como categoría literaria no tenía cabida dentro del discurso de la época, el erotismo era, en cambio, el término subversivo que en sí mismo resultaba pornográfico cuando era esgrimido por la voz de una mujer.

En la década de los sesenta se publicaron antologías eróticas como Prostibulario (1967), editada por Enrique Amorim, y Aqui la mitad del amor (1966), editada por Ángel Rama -la primera contiene un cuento escrito por una mujer y la segunda está compuesta por los relatos de varias escritoras uruguayas: Juana de Ibarbourou, Sylvia Lago, Armonía Somers, Clara Silva, María Inés Silva Vila y Giselda Zani-. Inés Arredondo, escritora mexicana de culto, publicó su primer cuentario de relatos eróticos en 1965: La señal. En ese mismo año Alejandra Pizarnik publicó La condesa sangrienta, una novela corta o cuento largo, según como se prefiera, que trata la figura de Erzébet Báthory desde la perversión sexual y el enfrentamiento entre eros y tánatos.

En la década de los setenta la irrupción de la narrativa erótica de mujeres en el marco de la producción literaria continental confluyó con las dictaduras militares, que empezaron a tomar el poder de más de la mitad de los países de la región. Reina Roffe, escritora argentina, después de publicar en 1976 una novela erótica que no tardó en ser prohibida, Monte de Venus, se exilió para huir de la censura de la dictadura de Videla. En España, tras la dictadura altamente represiva y puritana de Franco, surgió la colección de Tusquets La Sonrisa Vertical (1977) que le otorgó su primer premio a Susana Constante, escritora argentina que también se exilió en 1976, por la novela La educación sentimental de la señorita Sonia (1978).

La década de los ochenta -momento de retorno a la democracia-coincidió, no casualmente, con el despliegue de publicaciones de novelas y cuentos eróticos por

${ }^{1}$ Diane E. Marting en su ensayo "Dangerous (to) Women: Sexual Fiction in Spanish América", recogido en la antología de Sara Castro-Klaren Latin American Women's Narrative (2003), escribe que hasta 1960 las narradoras latinoamericanas no se atrevieron a abordar el deseo desde el sujeto femenino. 
parte de escritoras que estaban interesadas en quebrar la noción de lo femenino desde la reescritura del cuerpo. A causa de esta inclinación literaria varias autoras publicaron en los años ochenta ensayos que hablaban del eros y de la escritura, por ejemplo: Sitio a Eros (1980) de Rosario Ferré, "Las escritoras y el tema del sexo" (1989) de Tununa Mercado, "Algunas consideraciones sobre la mujer y la literatura" (1985) de Griselda Gambaro, etc. Y también obras narrativas como Bloyd (1984) de Liliana Heer, Los amores de Laurita (1984) de Ana María Shua, En breve cárcel (1981) de Silvia Molloy, La nave de los locos (1984) de Cristina Peri Rossi, Lo impenetrable (1984) de Griselda Gambaro, Amatista (1989) de Alicia Steimberg y Canon de alcoba (1989) de Tununa Mercado.

Como en Latinoamérica no hubo nunca espacio para la pornografía dentro de la discusión artística, el erotismo vino a representar la exquisita ejecución literaria de las perspectivas más escabrosas de la sexualidad y de sus significaciones políticas. Aunque la ejecución que llevó a cabo Osvaldo Lamborghini en su cuento El fiord (1969) no lo salvó de la censura -lo mismo ocurrió, más tarde, con su cuentario Sebregondi retrocede (1973). El problema para Lamborghini fue que se negó a sugerir lo sexual en su literatura y, en cambio, prefirió mostrarlo en toda su violencia y abyección -lo que su obra sugería era otras cosas, no el acto sexual-. Su narrativa era atrevida porque nombraba lo innombrable y se hacía cargo de crear los escenarios más duros y truculentos -siempre con un trasfondo político, en una especie de vuelta a la tradición originaria de la literatura pornográfica- sin elipsis y sin florituras en la construcción del lenguaje. Si para él, desde la centralidad de la voz masculina, este tipo de escritura estuvo vedada y le significó la marginalidad en su época, resulta fácil comprender por qué las escritoras optaron por un lenguaje menos agresivo para tratar, en el fondo, los mismos temas que Lamborghini. La década de los ochenta, en este sentido, fue un periodo de liberación en donde la lucha contra el autoritarismo y la creciente caída de las dictaduras militares latinoamericanas le dio espacio al erotismo y a la pornografía dentro de la literatura. No es casual que, durante la dictadura de Videla, los cuentos de Lamborghini hubieran tenido que circular a escondidas y que, dos años después de la caída del régimen, Luna caliente (1983) de Mempo Giardinelli se convirtiera en un bestseller.

\section{Literatura pornoerótica de los años ochenta}

La literatura pornoerótica es aquella que baila entre lo erótico y lo pornográfico, es un híbrido que saca, según le convenga, características de ambas categorías para construir un texto literario rebelde, irreverente, que difícilmente se ajusta a las dudosas delimitaciones de erotismo y pornografía, que juega con los límites de ambos géneros y con los límites de su propia representación; es iconoclasta, pero poética; cómica, pero grave; privada, pero pública. Es una literatura que incomoda, que inquieta; una a la que no se la puede llamar 'erótica' sin amputarle su carácter político, obsceno y abyecto, pero tampoco se la puede tildar de 'pornográfica' sin 
despojarla de su condición reflexiva y autorreflexiva ni de su uso exquisito, en algunos casos, del lenguaje -ni de su indiscutible condición de obra artística-. La literatura pornoerótica no es un género: es el quiebre de las condiciones que adopta el género del erotismo para distanciarse del no-género de la pornografía.

Hablar de literatura pornoerótica es referirnos a un corpus que demuestra que la distinción entre erotismo y pornografía es confusa, mutante e inestable. Las novelas y el cuento que he seleccionado para hablar de pornoerótica literaria en los años ochenta son obras que critican distintas instituciones -la del lenguaje, la de la política, la del género-, que subvierten identidades volviéndolas más flexibles y, a veces, indefinidas, que plantean el problema de la censura -instaurada en las dictaduras latinoamericanas-, que se burlan de los códigos de clase, que hacen del cuerpo y del placer una herramienta lúdica para mostrar y violentar la represión social y psicológica de sujetos que han experimentado el vivir en un sistema opresivo.

Griselda Gambaro escribió, en su exilio político debido a la dictadura argentina, Lo impenetrable, novela pornoerótica remake que pudo publicar en el año ochenta y cuatro en su país. Algo similar le ocurrió a Luisa Valenzuela, quien en 1977 escribió su relato "Cambio de armas" pero solo pudo verlo editado fuera de Argentina en el año ochenta y dos, mientras que La nave de los locos de Cristina Peri Rossi fue editada en el año ochenta y cuatro, cuando la autora ya se encontraba exiliada en Barcelona. Estas autoras escribieron a partir de la necesidad de desafiar a la autocensura arraigada en ellas mismas, a la literatura institucional y a las estáticas representaciones del deseo, de lo femenino y de lo masculino.

No haré una exégesis pormenorizada de las obras anteriormente citadas porque mi intención no es la de realizar un estudio literario minucioso, sino más bien encontrar lo que hay en cada una de ellas que excede los límites de lo permisible del marco erótico, lo que hay de transgresor y de político en el lenguaje del deseo, en la agencia de los sujetos-personajes y en la construcción de los escenarios públicos y privados en donde se desata la lujuria. Esto quiere decir que he encontrado nexos en las obras que he escogido, puntos interesantes para hablar de literatura pornoerótica.

\section{Androginia y bisexualidad: Lucía y Madame $\mathbf{X}$}

La nave de los locos de Cristina Peri Rossi es una novela que no ha sido catalogada como 'literatura erótica' puesto que los temas que la atraviesan son múltiples -la migración, el viaje, la censura, la crueldad, el falocentrismo-. Sin embargo, contrario a lo que se pueda argumentar al respecto, creo que La nave de los locos es una narración pornoerótica porque la presencia del deseo y del cuerpo, desde perspectivas transgresoras de lo prohibido, es su eje gravitacional. La novela construye, en realidad, una alegoría: cuenta la historia de Equis, un exiliado que viaja de un lugar a otro y que conoce a numerosos personajes en escenarios estrambóticos, sin embargo la narración se ve interrumpida constantemente por la descripción del Tapiz de la Creación de la Catedral de Gerona, como si la creación 
de la mitología cristiana medieval sirviera para comprender, de cierta forma, el viaje de Equis - un tránsito a través de varias opresiones-.

Una de las escenas más memorables de esta novela es la del encuentro sexual entre una supuesta Marlene Dietrich y una supuesta Dolores del Río frente a un público anhelante. Equis llevaba algún tiempo buscando a Lucía, una mujer a la que incidentalmente acompañó durante su proceso de aborto, y la encuentra en un local de espectáculos porno: "Sensacional espectáculo / tres pases continuos / pornosexy: / sensacionales travesties / ¿hombres o mujeres? / véalos y decida usted / mismo" (Peri Rossi, 1984:189). Equis se une al público que observa el show de una Lucía vestida de hombre interpretando a Marlene Dietrich a través de una cadena de imitaciones: “...imitando a Charlotte Rampling en Portero de noche, quien imitaba a Helmut Berger en La caída de los dioses, quien imitaba a Marlene Dietrich en El ángel azul" (191). Máscara tras máscara aparece Lucía andrógina y hace que Equis se sienta "subyugado por la ambigüedad" (195). Lucía/hombre/Marlene, indefinida ante los ojos de los espectadores e incluso ante los de Equis, poderosa, dueña de sí y constructora de sí, diferente a la que había acudido a aquella clínica para abortos y que había confesado odiar el azar al que era sometida cuando se acostaba con hombres -"La humillación es saberse víctima del azar, otra opresión" (176)-, inicia, en el escenario, un encuentro sexual con Dolores del Río, "un hombre disfrazado de mujer, o una mujer, un travesti, uno que había cambiado sus señas de identidad para asumir la de sus fantasías, alguien que se había decidido a ser quien quería ser y no quien estaba determinado a ser" (191).

La construcción narrativa de este encuentro sexual -en el que los dos protagonistas son seres de sexualidad y género subvertidos- se realiza con metáforas que remiten al mundo animal y a su violencia: el sexo entre Lucía/hombre/Marlene y Dolores del río está lleno de agresividad. La voz narradora se burla de las expectativas del lector cuando no es Lucía/hombre/Marlene la que monta a Dolores, sino viceversa "¿quién pensó que era Marlene quien iba a montarle?" (193). El público clama e interrumpe la descripción del acto pidiendo más, estirando sus brazos en un intento de asir lo inasible: las identidades indefinidas de los/las strippers. El mismo Equis, al igual que Madame X en Lo impenetrable de Griselda Gambaro, es una identidad en blanco, maleable y, por lo tanto, innombrable -la $\mathrm{X}$ es una variable que puede ser todo y nada-. La creación de una escena altamente excitante para el lector, no sugerida sino expuesta, con dos personajes de identidades XYZ, esto es, dos 'monstruos', otredades que se contraponen al público que los observa, hace que las categorías de lo erótico y lo pornográfico confluyan y que sus límites de separación se disipen. "La sensualidad (...) se manifiesta como tema privilegiado para estigmatizar lo diverso, que a menudo se atribuyen las marcas de la anormalidad y de un comportamiento excesivo" (Ressel Giordani, 2005: 48).

Precisamente en Lo impenetrable, Madame X representa el personaje que siente deseos de ser monstruo. Si bien ella jamás se plantea cambiar de sexo o de género, 
se siente atraída por la idea de serlo todo, de poder satisfacerse a sí misma encarnando los dos sexos. "Lamentó que su cuerpo no se desdoblara en mujerhombre, mujer-mujer, le hubiera gustado sentir su propio peso y no otro, penetrar y sentirse penetrada, ser en yin y el yang" (Gambaro, 1984: 20). Su bisexualidad patente en las relaciones que sostiene con su criada Marie, su cochero, entre otrosresponde a la necesidad de satisfacer el deseo inagotable que le generan las cartas eróticas de un pretendiente que, para su infortunio, sufre de eyaculación precoz y, además, parece solo poder excitarse cuando no hay ningún contacto físico de por medio. Esta imposibilidad de sostener relaciones sexuales con su amado hace que Madame X se hunda en la más profunda frustración. El epígrafe que abre la novela - escrito por la misma Griselda Gambaro- condensa el sentido de la espera de Madame X: "El gran inconveniente de la novela erótica es su dificultad para alcanzar el clímax literario".

Lo impenetrable aborda, a través del personaje de Madame $\mathrm{X}$, la problemática alrededor del concepto de identidad sexual. La clase social se muestra, en Lo impenetrable, como una característica definitoria de la 'identidad sexual' de los personajes. Madame X es una Mujer, pero Marie no: ella es, por encima de todo, una criada y, al serlo, no puede tener una "identidad de sexo": "Que Marie se asomara desnuda no provocaría escándalo, era de clase inferior, una criada" (36). El cuerpo político se devela en su estructura más básica, deshaciéndose del manto de la naturalización de su imagen, a través de la asignación de roles no solo sexuales y de género, sino también de clase. Durante el desarrollo de la novela Madame X se deja seducir, masturbar, acariciar por Marie sin participar activamente de esos encuentros porque eso sería inapropiado para alguien de su condición social. Sin embargo, el modelo de conducta sexual es distinto para Marie en tanto que es pobre y de clase trabajadora: el cuerpo de Marie es público; Marie puede -y debecomportarse como un ser que no es capaz de controlar sus impulsos ni sus deseos, puesto que no es un sujeto moral, y si es que posee una moral ésta es mucho más flexible y menos compleja que la de Madame X. No hay, por lo tanto, nada 'natural' en esta constitución de actitudes. Solo cuando Madame X puede, por fin, encontrarse con Jonathan -su amante epistolar-, y ve con horror que éste no es capaz de satisfacerla, accede gustosa $\mathrm{y}$, por primera vez, de forma activa a retozar con Marie; solo entonces opta por abandonar su rol y disfrutar de su cuerpo y del de los otros sin tapujos.

\section{La censura y la escritura del daño}

Las escrituras del daño recogidas tras $-\mathrm{y}$ durante- las dictaduras militares latinoamericanas son muchas y poseen múltiples formas. La literatura fue un espacio en donde poder rearticular un lenguaje de denuncia, pero también de reflexión acerca de los sistemas opresivos que coartaban la libre circulación de ideas; un espacio de cuestionamiento sobre los modelos políticos que operaban en todos los ámbitos vitales del ser humano, de deslegitimación de la autoridad tiránica 
que produjo muertos, desaparecidos y torturados, etc. La escritura en ese contexto intentó construir un lenguaje que pudiera dar cuenta del dolor físico y psicológico de una sociedad temerosa, agredida, por los aparatos de poder.

La literatura pornoerótica escrita por mujeres en el periodo de las dictaduras latinoamericanas no pudo circular con libertad y, por ello, varias autoras tomaron la decisión de exiliarse y publicar en el exterior. Griselda Gambaro escribió sobre Lo impenetrable que:

De regreso a la Argentina, a fines del 80, no me preocupé por editarla, no sólo por la censura imperante en ese entonces, sino también porque el carácter de esta novela iba muy a contramano con el clima opresivo que se vivía, y que yo alcancé a transgredir por la distancia y por la doble necesidad de la escritura y de una eventual rentabilidad que no se produjo. Sólo ahora, transcurridos tres años, pude corregir este texto y encarar su publicación. Quizá porque ahora, después de tanto dolor, sea posible acercarse a la literatura como a un lugar de esparcimiento, un lugar donde la imaginación, el desenfado y la desacralidad, sean pequeños aportes a una sociedad más lúdica y permisiva. (Gambaro 1984)

Estas autoras abordaron el tema del deseo y del cuerpo en sus creaciones para desafiar el discurso institucional a través de la mala palabra, el verbo prohibido, y encontrar en esta transgresión lingüística un lenguaje que pudiera expresar la experiencia de daño y de censura que se ejercía sobre las mentes y los cuerpos de los ciudadanos. Pero la escritura pornoerótica, además de ser una crítica en sí misma contra la noción de censura y de poder totalitario, representación y contrarepresentación, también hizo de esta crítica un tema translúcido en sus textos. Algunas de las obras pornoeróticas que fueron publicadas durante la década de los ochenta incluyen alusiones directas -cuando no tematizan- la represión como forma de control y ridiculizan la autoridad de la ley, la justicia y del poder ejecutivo, volviendo la mirada hacia la pornografía como la describe Lynn Hunt en The Invenction of Pornography: una categoría política en tanto que, como escribe Gorodischer, "La palabra es cambio. Y cuando una mujer escribe despojada de sumisión, la escritura que produce es siempre marginal, siempre implícita o explícitamente contestataria" (1985: 481). Precisamente La nave de los locos, Lo impenetrable y "Cambio de armas" son producciones literarias que a través del abordaje del sexo, el deseo y el placer tratan, "implícita o explícitamente", la violencia, la censura y el daño en las subjetividades y en los cuerpos.

La nave de los locos es una novela de personajes errantes. La condición de Equis, el protagonista, es la de ser extranjero, la de no pertenecer a ninguna parte, la del desarraigo, así como la de sus amigos. En el capítulo "El viaje, IX: La fábrica de cemento" se cuenta la historia del viajero Vercingetórix, amigo de Equis, enamorado de las enanas y de las niñas. El texto comienza de la siguiente manera: 
Vercingetórix desapareció una mañana cruda de agosto, en que el tiempo estaba algo frío, es verdad, él no había tomado ninguna disposición para combatirlo, ni preparar el viaje, porque hay viajes involuntarios que nos sorprenden en medio de nuestra candorosa hipótesis del tiempo y del espacio. Desaparecer deja entonces de ser un acto voluntario y se convierte en una actitud pasiva; nos desaparecen, decía Vercingetórix, las pocas veces que se refería al hecho. (Peri Rossi, 1984: 55)

Este desasosegante comienzo de capítulo desconcierta al lector que, hasta entonces, ha estado leyendo todo en clave de tránsito, de no-lugar, de nombres vacíos: de repente la escritura, con el tono irónico/humorístico que recorre toda la novela -y que resalta, paradójicamente, la crueldad de lo narrado-, se vuelve comprometida con la descripción de un escenario que en 1984 no es casual: la de la dictadura uruguaya, aquella que mantuvo a la autora lejos de su país, pero también la de todas las dictaduras de los años setenta en Latinoamérica. Con una voz narradora en tercera persona se cuenta la desaparición de Vercingetórix, el pánico de los vecinos al ver a los "saurios" (55), esos automóviles que cuando aparecían era para desaparecer gente, y el miedo que roía a todos por dentro y los obligaba a mirar hacia otro lado. Vercingetórix desaparece, el circo desaparece -y con él la diversión, el humor, la parodia-, pero su deseo por la enana del circo no se esfuma. Durante dos años él permanece 'desaparecido' -esa es su condición- en un campo a las afueras de la ciudad, entre una montaña y una fábrica de cemento que cubría de polvo toda la vegetación circundante: "La fábrica de cemento era un lugar de paso: los desaparecidos permanecían unas semanas, un par de meses allí, pero luego eran trasladados, otra vez, y Vercingetórix sabía que este viaje era el último..." (58). La palabra 'desaparecidos' se vuelve misteriosa, extraña, en la narración: Vercingetórix se llama a sí mismo de esa forma, se piensa desde esa categoría de ausencia, aunque él sabe muy bien dónde está, aunque sabe que continúa existiendo, solo se entiende y entiende el sitio en el que se encuentra a través de ese término. Ser un 'desaparecido' es, para Vercingetórix, el extrañamiento de dejar de existir para el mundo, de encontrarse en un lugar casi irreal en el que su dolor es intrasladable, invisible, para quienes están fuera del campo. 'Desaparecido', se llama a sí mismo, con plena conciencia de que lo han borrado, de que lo han expulsado, de que estuvo y ya no está, de que fue y ya no es. Tras ser liberado, Vercingetórix se exilia y va en busca del circo itinerante de la enana; huye porque sabe que volverán a desaparecerlo si se queda. Peri Rossi opta por no dejar de emplear el tono irónico/humorístico cuando narra las supuestas lecturas de poesía militar en los campos con el fin de ridiculizar a las autoridades y mostrar las contradicciones en los valores implantados por las dictaduras:

Vercingetórix observó que los oficiales y soldados tenían no sólo predisposición a la violencia, sino también a la poesía y al relato; muchas veces los sobrevivientes recibían la orden de reunirse en el patio, y el comandante -con la voz turbada por 
la emoción y los ojos centelleantes- les leía sus poemas, escritos en la soledad del campo cubierto de polvo de cemento. El aplauso era obligatorio y había sanciones y castigos para aquellos que aplaudieran sin entusiasmo suficiente o de manera poco sincera. (62)

Los 'desaparecidos' universitarios, cuenta la voz narradora, son forzados a realizar críticas académicas de ensalzamiento sobre los poemas de los militares: "El comandante y los oficiales se emocionaban tanto al escuchar el análisis y la descripción de la belleza de sus poemas que con frecuencia se echaban a llorar" (62). No es casual que Peri Rossi haya construido un escenario de tertulia literaria en un campo de desaparecidos: en Latinoamérica la noción de intelectual ha estado, desde siempre, intrínsecamente relacionada con la figura del escritor literario. El novelista o el poeta como actor social, pensador, ensayista, político, revolucionario, es un estereotipo históricamente consolidado. También el de la literatura como un arte de denuncia social, como espacio de resignificaciones, de crítica, de elaboración de un discurso del daño y como reivindicadora de la memoria. Sin embargo, esta idea del escritor total, del intelectual con las respuestas a las preguntas políticas más acuciantes, se resquebrajó durante los años setenta cuando se vio con más claridad que nunca la otra cara de la moneda, el carácter helmíntico de otro tipo de intelectualidad: la que apoyaba al poder y era enaltecida por el poder, la que se autoproclamaba élite. En La ciudad letrada, publicada en el mismo año que La nave de los locos, Ángel Rama dibuja el camino zigzagueante de las letras como institucionalizadoras de una visión particular de la realidad latinoamericana y la doble faceta de los intelectuales que "no sólo sirven a un poder, sino que también son dueños de un poder" (36). Peri Rossi se burla de la noción de intelectual de dictadura creando un oxímoron: militares poetas que recitan sus creaciones a los reclusos que torturan y matan sin remordimiento. Se trata de un capítulo estremecedor por las contradicciones que expone frente a la crueldad de un poder opresivo - a la entrada del campo hay un cartel que dice "MENTE SANA EN CUERPO SANO" y una 'desaparecida' está encargada de permanecer junto a él a tiempo completo, sin moverse, porque el polvo de la fábrica no deja de ensuciarlo y alguien tiene que limpiarlo-, pero esa crueldad no viene de mano de monstruos, sino de aspirantes a poetas, de hombres, seres humanos que son incapaces de articular un lenguaje de compasión o de empatía, y es eso, quizás, lo más perturbador del texto.

En Lo impenetrable la gran orgía que se produce en el Palacio de Justicia durante el juicio de Jonathan ridiculiza también a la autoridad, que, en este caso, son los representantes de la ley -el juez, el fiscal, el escribiente y los magistrados-. Mientras todos los presentes se excitan y ceden a sus impulsos sexuales por las descripciones que los testigos hacen del miembro de Jonathan, los personajes lanzan en sus diálogos críticas a la ley: 
-Pero la ley es inexorable. ¿Para qué existe si podemos negarla? ¿Para qué las celdas, los calabozos, el garrote y el hacha del verdugo si el enternecimiento no nos hace respetar la ley? [...]

-Estas leyes iguales para todos son dolorosamente imperfectas, leyes que castigan sin enmendar. ¿Hasta cuándo la justicia será deformada por la ley? (Gambaro, 1984: 107)

El mismo juez, representante de la justicia, es arrastrado a la orgía. A Gambaro no le basta con esto y continúa ridiculizándolo con un lenguaje humorístico y describiéndolo, en el capítulo siguiente, como un hombre autoritario que apostaba su sueldo mensual en un partido de cartas y que ansiaba volver a ser sodomizado.

Además de la parodia al ejercicio de la justicia y de sus representantes más relevantes, Gambaro hace una referencia directa a la novela erótica como género y a la censura:

[...] la última rogaba su asistencia a la presentación de una novela erótica, cuya publicación había sido tan demorada por prohibiciones, juicios y secuestros, que Madame X, que había tenido acceso diez años después de escrita a un ejemplar clandestino, la había encontrado completamente mondada de significados, lo que había sido de un erotismo excitante, vecino a la pornografía. (121)

Mencionar como anécdota dentro de la narración la censura a una novela erótica es una muestra de un texto autoconsciente $\mathrm{y}$, por lo tanto, que rompe el pacto ficcional para obligar al lector a pensar en el tipo de producto que tiene entre sus manos, pero además significa hacer visible el tema del silenciamiento de textos emparentado con la violencia dictatorial sobre los ciudadanos: no es casual que Gambaro escriba que la publicación de esa novela "había sido [...] demorada por prohibiciones, juicios y secuestros", enumeración sencilla en orden de represión creciente.

"Cambio de armas" de Luisa Valenzuela es un relato especialmente crítico con la violencia ejercida sobre los cuerpos y mentes durante la dictadura. Laura es una mujer torturada, desarmada, por un coronel que le hace creer que es su esposa y que la mantiene encerrada en un departamento para usarla como objeto sexual. Ella no recuerda su nombre ni su pasado. Su mente es un completo vacío de memoria y por ello es incapaz de articular su propio sufrimiento. Ve marcas en su cuerpo, marcas de tortura ejercida contra ella, pero no puede, ni quiere, entender su procedencia. A través de la imposibilidad de expresión de Laura -narrada por una voz en tercera persona-, se intenta dotar de lenguaje a alguien que carece de él: Laura no puede hablar, pero la voz narradora sí. La voz intenta construir una sintaxis que elabore la experiencia de daño de una mujer cuya conciencia y subjetividad ha quedado derruida. 
Y después están los objetos cotidianos: esos llamados plato, baño, libro, cama, taza, mesa, puerta. Resulta desesperante, por ejemplo, enfrentarse con la llamada puerta y preguntarse qué hacer. Una puerta cerrada con llave, sí, pero las llaves ahí no más sobre la repisa al alcance de la mano, y los cerrojos fácilmente descorribles, y la fascinación de otro lado que ella no se decide a enfrentar. (Valenzuela, 1982: 15)

Laura es Winston de 1984, un Winston que después de la tortura queda desarticulado e incapaz de decirse puesto que se ha enfrentado a la negación de sí. Ha sido su propio alter y, por eso, su humanidad se ha visto disminuida al dolor físico y a la humillación. Laura no tiene identidad porque en la tortura se la han arrebatado. Su situación, sin embargo, es todavía mucho más amarga que la de Winston: Laura es tratada con gentileza por su captor, no recuerda lo que él le hizo en el pasado, tiene las llaves de la puerta sobre la mesa, puede huir, pero sabe que 'no puede' hacerlo. Su prisión, su cárcel, toma la apariencia de un hogar. La violencia ejercida contra ella está disfrazada y por eso le cuesta verse a sí misma como una víctima. Sufre, pero no está segura siquiera del dolor que siente porque no tiene un lenguaje con el cual dotarlo de sentido. Los únicos momentos en los que sabe que existe y tiene plena consciencia de su cuerpo es cuando su captor la toca: "Es ésta su única forma de saberse viva: cuando la mano de él la acaricia o su voz la conmina: movéte, puta. Decíme que sos una perra, una arrastrada" (26). Solo se reconoce en esos nombres que él le otorga; nombres ofensivos, insultos que pretenden degradarla. Hay breves momentos en los que ella parece recordar de dónde proviene su dolor: cuando el coronel le lleva un rebenque para que lo utilicen en un juego sexual, Laura llora y grita y, como un animal asustado, se arrincona contra la pared, sugiriendo un pasado sórdido de agresión física. Al final del cuento el coronel la obliga a recordarlo todo y le devuelve un revólver que le pertenecía antes de ser torturada. Ese es el único momento del relato en el que Laura parece dejar su pasividad para levantar el arma y apuntar a un lugar que Valenzuela no precisa. Sea a donde sea que vaya la bala, si es que hay un disparo, "la llamada Laura" ha empuñado el revólver: ha actuado con lo que le estaba prohibido y ese es el primer paso hacia la reapropiación de un lenguaje y de un entendimiento de su experiencia.

\section{Conclusiones}

La literatura de la no-categoría pornoerótica de escritoras latinoamericanas en los años ochenta da cuenta de un intento por contra-representar las nociones de lo erótico y lo pornográfico, de 'la Mujer' y la relación que establece con su cuerpo, del lenguaje interdicto y su faceta subversiva, de lo público y lo privado, de la censura y el daño, en un contexto de cuestionamiento a la autoridad de las instituciones base de distintas sociedades. La represión instaurada por las dictaduras militares resultó en una eclosión de esta literatura del placer, de lo obsceno, de lo 
abyecto y de lo perverso, que se sostuvo con una poética de reapropiación de un lenguaje y de una escritura vedada para las escritoras por su condición de mujeres. Las circunstancias políticas, esto es, un contexto no democrático y de violaciones a los derechos humanos, dio pie a un remake del género erótico/pornográfico como forma de crítica política y de deslegitimación de la autoridad. Las autoras abordadas en este ensayo redescriben el género al incluir rezagos de una experiencia particular de dictaduras latinoamericanas y al realizar un sfumatto de la línea imaginaria que pretende dividir erotismo y pornografía.

\section{BIBLIOGRAFÍA}

CASTRO-KLAREN, Sara (ed.).

2003 Narrativa femenina en América Latina. Madrid: Iberoamericana.

GAMBARO, Griselda.

1984 Lo impenetrable. Buenos Aires: Torres Agüero Editor.

GORODISCHER, Angélica.

1985 "Contra el silencio por la desobediencia", Revista Iberoamericana, vol. LI, pp. 479-481.

HuNT, Lynn (ed.).

1993 The Invention of pornography. New York: Zone Books.

KIERAN, Matthew.

2001 "Pornographic Art", Philosophy and Literature, 2001, vol. 25 (1), pp. 31-45.

PERI Rossi, Cristina.

RAMA, Ángel.

1984 La nave de los locos. Barcelona: Seix Barral.

1984 La ciudad letrada. Hanover, N.H., U.S.A.: Ediciones del Norte.

RESSEL GIORDANI, Mónica.

2005 "El amor de los otros: la sexualidad monstruosa en el pensamiento griego", Un titulo para Eros. Granada: Universidad de Granada, pp. 47-68.

SONTAG, Susan.

2007 "La imaginación pornográfica", en Estilos radicales. Barcelona: Random House Mondadori, pp. 51-95.

VALENZUELA, Luisa.

1982 Cambio de armas. Hanover, N.H.: Ediciones del Norte.

YEHYA, Naief.

2012 Pornografia. México: Tusquets Editores. 